\title{
Fiziksel Yetersizlik, Umutsuzluk, Parasal Problem ve Sosyal Sermayenin Yalnızlık Hissi Üzerine Etkisi
}

\author{
DOI: $10.26466 /$ opus.568540
}

\author{
Gülsen Kıral* - Can Mavruk** - Ersin Kıral*** \\ * Doç. Dr., Çukurova Üniversitesi, İktisadi ve İdari Bilimler Fakültesi, Sarıçam/Adana/Türkiye \\ E-Posta: gkiral@cu.edu.tr \\ ORCID: 0000-0002-0541-0178 \\ ** Öğr. Gör., Niğde Ömer Halisdemir Üniversitesi, Niğde Sosyal Bilimler MYO, Niğde/Türkiye \\ E-Posta: mavruk.can1@gmail.com \\ ORCID: $\quad \underline{0000-0002-4084-7447}$ \\ *** Dr. Öğr. Üyesi, Çukurova Üniversitesi, İ.İ.B.F, Sarıçam/Adana/Türkiye \\ E-Posta: ekiral@cu.edu.tr \\ ORCID: 0000-0001-6040-1795
}

Öz

Bu çalışmanın temel amacı Adana'da yaşayan bireylerin yalnızlık hissine etki eden en önemli değişkenleri araştırmaktır. 2019 Ocak-Şubat aylarında yüz yüze yapılan basit rassal örnekleme ile belirlenen, Adana'da yaşayan 980 yetişkine; ekonomik, demografik, psikolojik, sosyolojik durumlarını ortaya çıkaracak 70 soruluk "Yaşam Kalite Analiz Anketi" uygulanmıştır. Açıklayıcı değişkenler içerisinde gelir, fiziksel yetersizlik, umutsuzluk, parasal problem ve insana güvenin yalnizlık hissini anlaml derecede etkilemesi beklenmektedir. Bağımlı değişken olan "yalnızlık hissi" iki değer alan kategorik bir değişken olması nedeni ile uygun ekonometrik model ikili lojistik regresyon modeli olarak belirlenmiştir. İncelemede ekonomik, demografik, psikolojik, sosyolojik durumu gösteren ve yalnızlı hissini etkilediği düşünülen tüm değiş̧kenler kullanılarak çok sayıda model oluşturulmuş ve en anlaml bulunan değişkenler üzerinden ikili lojisitk regresyon modeli oluşturulup yorumlanmıştır. Stata 14.2 programı yardımı ile marjinal etkiler hesaplanarak incelenen değişkenlerin yalnızlık hissi üzerindeki etki seviyeleri açıklanmıştır. Analiz sonucunda: 1) Gelir ve fiziksel yetersizlik yalnızlık hissini açıklamada en anlamlı değişkenler olarak elde edilmiştir 2) Demografik değişkenlerden; yaş, cinsiyet ve gelir; yalnızlık hissi üzerine etkisi olan değişkenler olarak belirlenmiştir 3) Sosyal sermaye değişkenleri içinden arkadaş ve aile bireyleri ile görüşme sıklı̆̆ından çok insana güven düzeyi yalnızlık hissini açıklamada daha etkili değişken olarak bulunmuştur.

Anahtar Kelimeler: Yalnıllk, Fiziksel yetersizlik, Sosyal sermaye, Lojistik regresyon, Adana 


\title{
The Effect of Physical Disability, Hopelessness, Monetary Problem and Social Capital on the Feeling of Loneliness
}

\begin{abstract}
The main purpose of this study is to investigate the most important variables that affect the loneliness of individuals living in Adana. In January-February 2019, a 70-question Life Quality Analysis Survey conducted by simple random sampling to reveal economic, demographic, psychological and sociological status was applied to 980 adults living in Adana. Among the explanatory variables, income, physical disability, hopelessness, financial problems and trust in human beings are expected to significantly affect the feeling of loneliness. As the dependent variable "loneliness" is a categorical variable with two values, the appropriate econometric model is determined as Binary Logistic Regression Model. In the investigation, a large number of models were formed by using all variables showing economic, demographic, psychological, sociological status and thought to affect the feeling of loneliness, and a binary logistic regression model was created and interpreted on the most significant variables. With the help of Stata 14.2 program, marginal effects were calculated and the effect levels of the variables on loneliness were explained. As a result of the analysis: 1) Income and physical disability were obtained as the most significant variables explaining the feeling of loneliness; 2) Demographic variables such as age, gender and income have an effect on the feeling of loneliness; 3) Among social capital variables, the level of trust in people rather than the frequency of seeing friends and family members was found to be more effective in explaining the feeling of loneliness.
\end{abstract}

Keywords: Loneliness, Physical disability, Social capital, Logistic regression, Adana 


\section{Giriş}

Adana' da yalnızlık üzerine yapılan bazı çalışmalar literatürde bulunmaktadır. Adana'ya bağlı devlet okullarında öğrenim görmekte olan 899 lise öğrencisi üzerine yapılan araştırma sonucunda yüksek şiddet eğilimi olan ergenlerin yalnızlık düzeyleri yüksek bulunmuştur (Avcı ve Yıldırım, 2014); UCLA yalnızlık ölçeği kullanılarak Çukurova Üniversitesi öğrencilerinin mizaç tarzının yalnızlığı nasıl etkilediği tahmin edilmiştir (Çeçen, 2007). Ancak, Adana' da yetişkinlerin fiziksel yetersizlik, umutsuzluk, parasal problem ve sosyal sermayelerinin yalnızlık hissi üzerine etkisi literatürde araştırılmamıştır. Bu çalışmada yalnızlık, sosyal izolasyonun objektif durumundan ayrı olarak sübjektif bir durum olarak ele alınmıştır. Bu araştırmanın temel amacı Adana' da yaşayan yetişkin bireylerin yalnızlık hisleri üzerine etkili olan değişkenleri ortaya çıarmak ve etkilerini ölçmektir. Bu amaçla logit (üstünlük oranının doğal logaritması) model kullanılarak katsayılar, exp (logit) kullanılarak yalnızlık hissinin üstünlük oranları ve açıklayıcı değişkenlerin yalnızlık hissi üzerine ortalama marjinal etkileri hesaplanmıştır. Bu hesaplamalardan faydalanılarak yalnızlığı açıklayan en önemli değişkenler bulunmuştur. Bu çalışmada cinsiyet, yaş, aylık gelir, umutsuzluk, fiziksel yetersizlik, insana güven ve parasal problem değişkenlerinin yalnızlığı açıklamada anlamlı etkiye sahip olmaları beklenmektedir.

Yalnızlık terimi, ilk olarak 1939'da Sigmund Freud tarafından, bir yalnızlık deneyiminden sonra bir kişinin tamamen değişebilecek olan iç yapısını tanımlamak için kullanılmıştır (Bekhet, Zauszniewski, ve Nakhla, 2008, s.208). 1959'da Fromm-Reichmann yalnızlık sıkıntısını, felç eden umutsuzluk ve değiştirilemez boşluk olarak tanımlamıştır (Rokach, 1988, s.540). Literatürde yalnızlık farklı bir şekilde kavramsallaştırılmış ve birçok disiplinde farklı yöntemler kullanılarak farklı değişkenlerle ilişkilendirilmiştir. Weiss (1973)'e göre yalnızlık, yalnız kalmaktan değil, kesin ihtiyaç duyulan bir ilişkiden veya ilişkilerden yoksun kalmaktan kaynaklanır. Yalnızlık, artan ölüm riski (Holt-Lunstad, Smith, Baker, Harris ve Stephenson, 2015), kalp hastalıkları (Valtorta, Kanaan, Gilbody, Ronzi ve Hanratty, 2016), yüksek tansiyon (Hawkley, Thisted, Masi ve Cacioppo, 2010), sağlıksız davranışlar (Lauder, Mummery, Jones ve Caperchione 2006) ve depresyon (Cacioppo, Hawkley ve Thisted, 2010) ile 
ilişkilendirilmiştir. Bir bireyin yalnızlığı hem dış hem de iç özellikleri ile değerlendirilir. Burada, diş özellikler gözlenebilir sosyal koşullar ya da nesnel yalnızlık: diğer insanlarla anlamlı ilişkilerin azlığı veya yokluğudur (Zavaleta, Samuel ve China, 2014, s.9). Yalnızlık her zaman belirli bir ilişki türünün yokluğuna bir cevap veya daha kesin olarak, belirli bir ilişkisel hükmün bulunmamasına cevap olarak görünmektedir. İçsel özellikler, güven, ilişkilerden memnuniyet ve yalnızlık olarak bilinen öznel deneyim, yani "ideal ve algılanan sosyal ilişkiler arasındaki tutarsızlıktan kaynaklanan sıkıntı" dahil olmak üzere gözlem ile ölçülemeyen olguyu ifade eder (Hawkley ve Cacioppo, 2009). Psikolojik perspektif ile yalnızlık, samimi ve sosyal ihtiyaçların yokluğuna verilen tepkileri içeren karmaşık bir duygu dizisidir ve korelasyon çalışmaları yakın bir arkadaşın veya romantik bir ortağın yalnızlık riski taşıyanları korumak için yeterli olabilir. Yalnız hissetme olasılığı en yüksek olan insanlar utangaçlık, düşük sosyal yeterlilik, duygusal istikrarsızlık bildirenlerdir (Ernst ve Caccioppo, 1999). Yalnızlık bir bireyin tatmin edici ilişkilere sahip olmadığının öznel hissidir. Sadece bireyler kendi iç hisleri ile yalnızlığın varlığını ve derecesini söyleyebilir. Yalnızlık deneyimi insan ilişkilerinde beklentilerle ilgilidir ve genellikle kültürel olarak tanımlanır (Wenger, Davies, Shahtahmasebi ve Scott, 1996; Andersson, 1998). Yaşlı kişilerin yalnızlığı da literatürde geniş bir yer kaplar. Uzmanlık tez çalışmasında Pradhan (2016, s.6) yalnızlığı azaltmak için yaşlı yetişkinlerde uygulanabilecek olan sosyal bütünleşme davranışlarını araştırmıştır. Bu çalışma, Amerika Birleşik Devletleri'nde 65 ile 84 yaşları arasındaki Amerikan yetişkinleri üzerinde odaklanmıştır. Singh ve Misra (2009), UCLA yalnızlık ölçeği, Beck'in depresyon ölçeği ve Eysenck'in sosyalleşebilme alt ölçeğini kullanarak yaşlı erkeklerin yalnızlığı ile sosyalleşebilme arasında anlamlı olmayan negatif bir korelasyon ve yaşlı kadınların yalnızlığı ile sosyalleşebilmeleri arasında anlamlı olmayan pozitif bir korelasyon bulmuştur. Engellilik normal bir faaliyeti gerçekleştirme (yürüyüş gibi) kısıtlamaları ile ilgilidir. Etkilenen organa veya bedensel sisteme bağlı olarak, fiziksel engeller hareket kabiliyeti, görme veya işitme yeteneği ile ilgili sorunlara neden olabilir ve sonuçta bir insanın başkalarıyla iletişim kurabilme kabiliyeti etkilenebilir veya azalabilir (Rokach, 2012, s.148). Engellilik, bir kişinin sosyal ağını olumsuz yönde etkiler ve sonuç olarak, bu yalnızlı̆̆a yol açabilir. Engellilik, 
mümkün olan faaliyet türlerini olumsuz etkileyebileceği ve cinsellik ile ilgili sorunlara yol açabileceği için duygusal yakınlık ve mahremiyet üzerinde olumsuz bir etkiye sahip olabilir. Gerçekten de engellilik, daha yüksek düzeyde duygusal yalnızlık ile ilişkilidir (Rokach, 2014). Cacioppo ve Patrick (2008, s.14) yalnızlığın güçlü etkilerinin üç karmaşık faktörden kaynaklandığını gösterir: sosyal kopukluk hassasiyet seviyesi, izole hissi ile ilişkili olan duyguları kendi düzenleme yeterliği ve başkalarının zihinsel temsilleri ve beklentileri. Düşük güven inancı, çocukluktan yetişkinliğe yalnızlığı teşvik eder (Rotenberg vd., 2010, s.1). Çeçen ve Cenkseven (2007, s.113-114); Ryff'in psikolojik refah ölçeği kullanarak UCLA-R yalnızlığını tahmin etmiştir. Başkaları ile pozitif ilişkileri yalnızlığın en iyi tahmin edicisi olarak ve hayattaki amacı ise ikinci en iyi tahmin edici olarak bulmuştur.

Finansal problemler nedeniyle birçok insan yalnızlık duygusu çektikleri (Lopota, 1969, s.256) göz önüne alındığında yalnızlık üzerine sosyal sermayenin nasıl bir etki yaptığının belirlenmesinin önemli olduğu düşünülebilir. Diğer sermaye türlerinin (örneğin, fiziksel veya insan) kavramsallaştırılmasına paralel olarak, teorisyenler "sosyal sermaye" terimini, bir insanın güce veya kaynaklara erişme veya üretim seviyesini ve verimliliğini arttırma yeteneğini geliştirmek için bir girdi olarak sosyal bağlantının sahip olduğu öneme işaret etmek için kullanırlar (Coleman, 1988, s.100). Yaşlılıkta yalnızlık (Danış, 2009, s.73) dışında bireylerin parasal problemlerinin yalnızlık hissi üzerine etkisi de literatürde yer almaktadır. Son yıllarda Adana' da işsizlik oranlarının yüksek seviyede kalıcılığ 1 (Kıral ve Mavruk, 2017, s.133), nüfusun artması ve toplumun yoksullaşması parasal problemleri beraberinde getirmiştir. Türkiye İstatistik Kurumu (TÜIK), 2016 yılı gelir ve yaşam koşulları araştırması bölgesel sonuçlarına göre her bölge için eşdeğer hane halkı kullanılabilir fert medyan gelirin yüzde 50'si temelinde hesaplanan yoksulluk sınırına göre, gelire dayalı göreli yoksulluk oranının en yüksek olduğu bölgeler yüzde 15,9 ile Adana ve Mersin çıkmıştır.

\section{Metodoloji}

Basit rassal örnekleme ile seçilen Adana'da ikame eden 18-47 yaş aralığındaki kişilere uygulanan anket 2019 Ocak-Şubat aylarında yapılmış ve 
doğru olarak doldurulan 980 anket değerlemeye alınarak analizler gerçekleştirilmiştir. Yalnızlık hissini etkileyecek anlamlı değişkenler (demografik, ekonomik, sağlık, mekânsal, sosyal sermaye, fiziksel yetersizlik, amacın gerçekleşmeme ihtimali (umutsuzluk), parasal problem (maddi sıkıntı), genel olarak insanlara güven...) kullanılarak en uygun ekonometrik model oluşturulmuştur.

$\mathrm{Bu}$ anket için gerekli olan örneklem büyüklüğünü bulmak için

$$
n=\frac{\chi^{2} N p q}{d^{2}(N-1)+\chi^{2} p q}
$$

formülü kullanılmıştır. Bu formülde $n$ örneklem büyüklüğü, $\chi^{2}$ tablo değeri (\%5 anlamlılık için 3.841), N kitle büyüklüğü, kitle oranı p 0.5 kabul edilmiştir ve $\mathrm{d}$ doğruluk derecesi (hata payı) 0.05 alınmıştır. (1) nolu formülden

$$
n=\frac{3.841(980)(0.5)(0.5)}{(0.05)^{2}(980-1)+3.841(0.5)(0.5)} \approx 277
$$

bulunur. \%5 hata payı ile örneklem büyüklüğü minimum 277 olmalıdır. Bu araştırmanın anketine katılan 980 yetişkin ile minimum örneklem büyüklüğü şartı sağlanmıştır.

Aylık gelir, ilk evlilik yaşı ve ailede birlikte yaşanılan kişi sayısı haricinde açıklayıcı kukla değişkenler sıralı kategorik göstergeler olarak kodlanmıştır.

Demografik değişkenlerden yaş için 18-23, 24-29, 30-35, 36-41 ve 42-47 kategorileri sırasıyla 1, 2, 3, 4 ve 5 ile, cinsiyet için kadın 0 ve erkek 1 ile,

medeni hal için bekâr 1 , evli 2 , boşanmış veya ayrılmış 3 , dul 4 ve nişanlı 5 ile ve eğitim durumu için okuryazar değil 1, ilköğretim 2, lise 3, meslek yüksekokul 4, üniversite 5, yüksek lisans-doktora 6 ile kodlanmıştır. İlk evlilik yaşı ve ailede birlikte yaşanılan kişi sayısı sayısal ölçekli (numeric type-scale measure) olarak ankete dâhil edilmiştir. Ekonomik değişkenlerden iş durumu için ücretli çalışan 1, şu anda çalışmayan 2, ücretsiz aile işçisi 3, on iki aydan kısa süredir işsiz 4, hastalık ve sakatlıktan işsiz 5, emekli 6, ev hanımı 7, öğrenci 8 ile, çalışılan alan için özel 1, kamu 2, yarı özel 3, işsiz 4, işveren 5, vakıf-dernek 6 ile kodlanmıştır. Aylık gelir sayısal ölçekli olarak ankete dâhil edilmiştir. Sağlık durumu kukla değişkeni çok kötü 1, kötü 2, ne iyi ne de kötü 3, iyi 4 ve çok iyi 5 ile kodlanmıştır. Fiziksel yetersizliği ve umutsuzluğu ölçmek için 
"Fiziksel yetersizliğim var" ve "Amacımın gerçekleşme ihtimali yoktur" sorularına ne ölçüde katıldıkları sorulmuş, "kesinlikle katılmıyorum", "katılmiyorum", "ne katıliyorum ne de katılmıorum", "katılıyorum" ve kesinlikle katılıyorum" seçenekleri sunulmuştur. Bu çalışmada "amacımın gerçekleşme ihtimali yoktur" umutsuzluk olarak kabul edilmiştir. Sosyal sermayeyi ölçmek için "Genelde insanlara ne ölçüde güveniyorsunuz?" sorusu yöneltilmiş ve cevaplar "hiç güvenmiyorum", "güvenmiyorum", "ne güveniyorum ne de güvenmiyorum", "güveniyorum", "çok güveniyorum" şeklinde kategorize edilmiştir. Cevaplar sırasıyla 1, 2, 3, 4, 5 ile kodlanmıştır. Daha sonra insana güven değişkeninin ilk ve son iki kategorisi birleştirilerek beş olan kategori sayısı üçe düşürülmüştür. Yalnızlığı ölçmek için "Geçen bir hafta boyunca çok yalnız ve diğer insanlardan uzak hissetiniz mi?" sorusu için "hayır" veya "evet" seçenekleri sunulmuştur. Cevaplar sırasıyla 0 ve 1 ile kodlanmıştır.

Bu çalışmada, iki kategorili bağımlı değişken olarak ifade edilen belirli gruplara üye olma durumunu en iyi açılayan bağımsız değişkenler kombinasyonunu belirlemeye yönelik ikili (binary) lojistik regresyon analizi yardımı ile ekonomik, demografik, psikolojik, sosyolojik durumu gösteren tüm değişkenler kullanılarak yalnızlık hissini etkilediği düşünülen değişkenler üzerinden literatüre dayalı olarak çok sayıda model oluşturulmuş ve en anlamlı bulunan değişkenler üzerinden ikili lojistik regresyon modeli oluşturulup yorumlanmıştır.

Lojistik regresyon analizinin temel odağı, bireylerin hangi grubun üyesi olduğunu kestirmede bir regresyon denklemi oluşturmaktır. Amaç, kategorik bağımlı değişkenin değerini tahmin etmek olduğundan, burada yapılmaya çalışılan iki (ya da daha fazla) gruba ilişkin "üyelik" tahminidir (Mertler ve

Vannatta, 2005). Bu nedenle analizdeki amaçlarımızdan birincisi sınıflandırma, diğerinin ise bağımlı ve bağımsız değişkenler arasındaki ilişkileri araştırmaktır.

Lojistik regresyon bağımlı değişkene ilişkin verilerin dağılımının bir ya da daha fazla bağımsız değişkenle doğrusal olmayan ilişki gösterdiğinin bilinmesi ya da beklenmesi özellikle yararlıdır.

Model tahmininde bağımlı değişkenin iki kategorili bir değişken olması nedeni ile ikili lojistik regresyon kullanılmıştır. Bütün logit modeller, 
bağımsız değişkenlerle doğrusal olarak ilişkili olan bir sürekli bağımlı latent değişken $\left(\mathrm{Y}^{*}\right)$ varsayar:

$$
\mathrm{Y}^{*}=\mathbf{X} \beta+\varepsilon \quad \varepsilon \sim \operatorname{Logit}\left(0, \lambda^{2} / 3\right)
$$

Logit modelde gözlemlenen değerler

$$
\begin{aligned}
& y_{i}^{*} \leq 0 \rightarrow y_{i}=0 \\
& 0<y_{i}^{*} \rightarrow y_{i}=1
\end{aligned}
$$

Logit model için bağımlı değişken "evet" veya "hayır" şeklinde iki seçeneklidir. Bu modelde hedef grup 1 ile kodlanmıştır. Grup üyeliği SPSS 18 programı kullanılarak tahmin edilmiştir. Program hedef grupta üyeliği olmayan bir bireyi hedef grupta veya hedef grupta olduğunu beyan eden bir bireyi hedef grupta değil yönünde tahmin edebilir. Sınıflandırma eşik değeri standart 0.5 kullanılır. Olasılıklar (predictive probabilities) 0.5 ten büyük ise 1 grubuna ve $0.5^{\prime}$ ten küçük veya eşit ise 0 grubuna düşeceği tahmin edilir. Sonuç olarak, grup üyeliği tahminlerinin bir doğruluk oranı bulunur. Bu model üstünlük oranı p/(1-p)'nin doğal logaritmasını (logit) bağımsız değişkenlerin doğrusal bir fonksiyonu olarak ifade eder (Kalayc1, 2014). Logit modellerde $Y \in\{0,1\}$ bağımlı değişken sürekli bir latent değişkene $Y^{*} \in(-\infty, \infty)$ dönüştürülür. Bunun için üstünlük oranı kullanılır. Bir olay p olasılığı ile gerçekleşiyorsa bu olayın gerçekleşme üstünlük oranı $O(p)=p /(1-p)^{\prime}$ dir. $p=0$ ise $O(p)=0, p=1 / 2$ ise $O(p)=1, p=1$ ise $\mathrm{O}(\mathrm{p})=\infty$ olur. Böylece $\mathrm{O}:[0,1] \rightarrow[0, \infty)$ olur. Üstünlük oranının doğal logaritması alınırsa $\log [\mathrm{O}(\mathrm{Y})]=\log [\mathrm{Y} /(1-\mathrm{Y})] \operatorname{logit}$ fonksiyonu $\operatorname{logit}(\mathrm{Y})$ elde edilir.

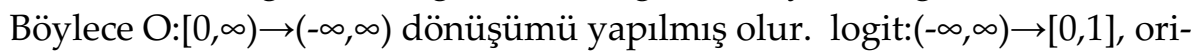
jinal Y'ye geri dönüşümü $\log [Y /(1-Y)]=X \beta$ dan $Y=\exp (\mathbf{X} \beta) /(1+\exp (\mathbf{X} \beta))$ olarak sağlar.

Demografik değişkenlerle birlikte umutsuzluk, fiziksel yetersizlik, parasal problem, sosyal sermaye nominal bağımsız değişkenleri ve yalnızlık bağımlı

değişkeni için bir logit model oluşturulmuştur. Bu modele göre bir bireyin yalnız hissetme olasılığ $\mathrm{P}(\mathrm{Y}=1)=1 /(1+\exp (-X \beta))$ ile hesaplanır.

$\mathrm{Bu}$ formülde $\mathbf{X} \beta=\beta_{0}+\beta_{1} \mathrm{D} 1+\beta_{2} \mathrm{D} 2+\beta_{3} \mathrm{SE}+\beta_{4} \mathrm{AG}+\beta_{5} \mathrm{FY}+\beta_{6} \mathrm{UM}+\beta_{7} \mathrm{PP}+\beta_{8} \mathrm{IG}$ olup burada;

D1: Cinsiyet, D2: Yaş, SE: Aylık Gelir, FY: Fiziksel Yetersizlik, UM: Umutsuzluk, PP: Parasal Problem, IG: İnsana Güven değişkenlerini göstermektedir. Logit modellerde marjinal etki, tüm diğer değişkenler 
kendi değerlerinde sabit (ortalamalarında) tutulduğunda, $X_{k} y 1 ; P(Y=1 \mid X)$ olasılığ 1 ile ilişkilendiren olasılık eğrisinin eğimidir. Buna göre $F Y^{\prime}$ in yalnızlık üzerine marjinal etkisi $\partial \mathrm{P}(\mathrm{Y}=1) / \partial \mathrm{FY}=\left[\exp (\mathbf{X} \beta) /\left(1+\exp (\mathbf{X} \beta)^{2}\right](\partial(\mathbf{X} \beta) /\right.$ $\partial F Y)=\left[\exp (\mathbf{X} \beta) /\left(1+\exp (\mathbf{X} \beta)^{2}\right] \beta_{1}=\mathrm{P}(\mathrm{Y}=1)[1-\mathrm{P}(\mathrm{Y}=1)] \beta_{1}=\mathrm{P}(\mathrm{Y}=1) \mathrm{P}(\mathrm{Y}=0) \beta_{1}\right.$ ile hesaplanabilir.

Bu çalışmada marjinal etkiler STATA/IC 14.2 programı kullanılarak hesaplanmıştır. İkili bağımsız değişkenle marjinal etki kesikli değişimi ölçer. Yani ikili bağımsız değişken 0'dan 1'e değişirken olasılıkların tahmininin (predictive margins) nasıl değişeceğini gösterir. Kategorik değişkenler için marjinal etki, diğer tüm değişkenleri kendi değerlerinde sabit tutarak kategorik değişken $0^{\prime}$ dan $1^{\prime}$ e değiştikçe $\mathrm{P}(\mathrm{Y}=1)^{\prime}$ in nasıl değiştiğini gösterir (Williams, 2012: 323). Yani, bir $X_{k}$ kategorisel değişken için marjinal etki $=P\left(Y=1 \mid X, X_{k}=1\right)-P\left(Y=1 \mid X, X_{k}=0\right)$ eşitliği ile hesaplanır.

\section{Bulgular}

Açıklayıcı değişkenlerin tanımlayıcı istatistikleri Tablo 1'de gösterilmiştir.

Tablo 1. Açıklayıcı Değişkenlerin Tanımlayıcı İstatistikleri

\begin{tabular}{llllll}
\hline Açıklayıc Değişken & $\mathbf{N}$ & Aritmetik Ortalama & Std. Sapma & Min & Maks. \\
\hline Yaş & 980 & 1.86 & 1.010 & 1 & 5 \\
Cinsiyet & 980 & 0.44 & 0.497 & 0 & 1 \\
Aylık Gelir & 980 & 1.24 & 0.447 & 1 & 3 \\
Umutsuzluk & 980 & 2.08 & 1.127 & 1 & 5 \\
Parasal problem & 980 & 3.14 & 1.323 & 1 & 5 \\
Fiziksel yetersizlik & 980 & 2.08 & 1.180 & 1 & 5 \\
İnsana güven & 980 & 1.72 & 0.725 & 1 & 3 \\
\hline
\end{tabular}

Tablo 2'de ankete katılanların yaklaşık olarak $\% 42$ 'sinin parasal problem yaşadığı, \%14'ünün bir fiziksel yetersizliği olduğu, \%13'ünün umutsuz olduğu ve \%45'inin insanlara güvenmediği görülmektedir. 
Tablo 2. Bă̆ımsız Değişkenlerin Frekans (N) ve Yüzdeleri (\%)

\begin{tabular}{|c|c|c|c|c|c|c|c|c|c|c|}
\hline & & & & \multicolumn{3}{|c|}{$\begin{array}{l}\text { Parasal problemler } \\
\text { yaşıyorum }\end{array}$} & \multicolumn{2}{|c|}{$\begin{array}{l}\text { Fiziksel } \\
\text { yetersizliğim var }\end{array}$} & \multicolumn{2}{|c|}{ Umutsuzluk } \\
\hline & & & & $\mathrm{N}$ & $\%$ & & $\mathrm{~N}$ & $\%$ & $\mathrm{~N}$ & $\%$ \\
\hline \multicolumn{4}{|c|}{ Kesinlikle katılmıyorum } & 149 & 15.20 & & 423 & 43.20 & 383 & 39.08 \\
\hline \multicolumn{4}{|c|}{ Katılmıyorum } & 159 & 16.20 & & 241 & 24.60 & 299 & 30.51 \\
\hline \multicolumn{4}{|c|}{ Ne katılıyorum ne de katılmıyorum } & 263 & 26.80 & & 177 & 18.10 & 168 & 17.14 \\
\hline \multicolumn{4}{|c|}{ Katılıyorum } & 219 & 22.30 & & 97 & 9.90 & 94 & 9.59 \\
\hline \multicolumn{4}{|c|}{ Kesinlikle katılıyorum } & 190 & 19.40 & & 42 & 4.30 & 36 & 3.67 \\
\hline \multirow[t]{3}{*}{ Toplam } & & & & 980 & 100 & & 980 & 100 & 980 & 100 \\
\hline & \multicolumn{2}{|l|}{ Yaş } & Cinsiyet & & \multicolumn{2}{|c|}{ Aylık Gelir } & \multicolumn{4}{|c|}{ İnsana güven } \\
\hline & $\mathbf{N}$ & $\%$ & $\mathbf{N}$ & $\%$ & & $\mathbf{N}$ & $\%$ & & $\mathbf{N}$ & $\%$ \\
\hline $18-23$ & 448 & 45.7 & K 549 & 56 & $-2020 \mathrm{TL}$ & 747 & 76.2 & $\begin{array}{l}\text { Güven } \\
\text { miyoru } \\
\text { m }\end{array}$ & 436 & 44.5 \\
\hline $24-29$ & 334 & 34.1 & E 431 & 44 & $\begin{array}{l}2020- \\
6000\end{array}$ & 226 & 23.1 & Nötr & 386 & 39.4 \\
\hline $30-35$ & 115 & 11.7 & & & $6000+\mathrm{TL}$ & 7 & 0.7 & $\begin{array}{l}\begin{array}{l}\text { Güveni } \\
\text { yorum }\end{array}\end{array}$ & 158 & 16.1 \\
\hline $36-41$ & 58 & 5.9 & & & & & & & & \\
\hline $42-47$ & 25 & 2.6 & & & & & & & & \\
\hline Toplam & 980 & 100 & 980 & 100 & & 980 & 100 & & 980 & 100 \\
\hline
\end{tabular}

Tablo 3. Yalnızlı̆̆ın Bă̆ımsız Değişkenler ile Çapraz Tabloları

\begin{tabular}{|c|c|c|c|c|c|c|c|c|c|c|c|}
\hline \multicolumn{6}{|c|}{ Umutsuzluk } & \multicolumn{6}{|c|}{ Fiziksel yetersizliğim var } \\
\hline $\begin{array}{l}\text { Yal- } \\
\text { nizlik }\end{array}$ & 1 & 2 & 3 & 4 & 5 & $\begin{array}{l}\text { Top- } \\
\text { lam }\end{array}$ & 1 & 2 & 3 & 4 & 5 \\
\hline 0 & 214 & 146 & 64 & 35 & 14 & 473 & 241 & 110 & 72 & 36 & 14 \\
\hline 1 & 169 & 153 & 104 & 59 & 22 & 507 & 182 & 131 & 105 & 61 & 28 \\
\hline $\begin{array}{l}\text { Top- } \\
\text { lam }\end{array}$ & 383 & 299 & 168 & 94 & 36 & 980 & 423 & 241 & 177 & 97 & 42 \\
\hline \multicolumn{7}{|c|}{ Parasal problemler yaşıyorum } & \multicolumn{5}{|c|}{ İnsana güven } \\
\hline \multicolumn{2}{|c|}{ Yalnızlık } & 1 & 2 & 3 & 4 & 5 & \multicolumn{2}{|c|}{ Toplam } & 1 & 2 & 3 \\
\hline \multicolumn{2}{|l|}{0} & 87 & 87 & 130 & 101 & 68 & \multicolumn{2}{|l|}{473} & 189 & 197 & 87 \\
\hline \multicolumn{2}{|l|}{1} & 62 & 72 & 133 & 118 & 122 & \multicolumn{2}{|l|}{507} & 247 & 189 & 71 \\
\hline \multicolumn{2}{|l|}{ Toplam } & 149 & 159 & 263 & 219 & 190 & \multicolumn{2}{|l|}{980} & 436 & 386 & 158 \\
\hline \multicolumn{7}{|l|}{ Yaş } & \multicolumn{5}{|c|}{ Aylık Gelir } \\
\hline \multicolumn{2}{|c|}{ Yalnızlık } & $18-23$ & $\begin{array}{l}24- \\
29\end{array}$ & $\begin{array}{l}30- \\
35\end{array}$ & $\begin{array}{l}36- \\
41 \\
\end{array}$ & $\begin{array}{l}42- \\
47\end{array}$ & Toplam & -2020 & \multicolumn{2}{|c|}{$\begin{array}{l}2020- \\
6000\end{array}$} & $6000+$ \\
\hline \multicolumn{2}{|l|}{0} & 197 & 158 & 69 & 34 & 15 & 473 & 331 & \multicolumn{2}{|c|}{136} & 6 \\
\hline \multicolumn{2}{|l|}{1} & 251 & 176 & 46 & 24 & 10 & 507 & 416 & \multicolumn{2}{|c|}{90} & 1 \\
\hline \multicolumn{2}{|l|}{ Toplam } & 448 & 334 & 115 & 58 & 25 & 980 & 747 & & & 7 \\
\hline
\end{tabular}

Yalnızlığın umutsuzluk, fiziksel yetersizlik ve parasal problemler ile çapraz tabloları Tablo 3'te verilmiştir. Yalnızlığın umutsuzluğa bağlı 
koşullu olasılı̆g $1 \mathrm{p}=\mathrm{P}(\mathrm{y}=1 \mid$ umutsuzluk $)$ şeklinde yazılır. Buna göre yalnızlık üstünlük oranı $\mathrm{p} /(1-\mathrm{p})=(507 / 980) /(1-507 / 980)=0.517 /(1-$ $0.517)=0.517 / 0.483=1.07$ bulunur.

Açıklayıcı değişkenler arasındaki korelasyon katsayıları Tablo 4'te gösterilmiştir. Yaş, cinsiyet, aylık gelir, insanlara güven ve yalnızlık arasında istatistiksel olarak negatif bir ilişki varken, umutsuzluk ile yalnızlık arasında pozitif bir ilişki vardır. Pehlivan vd. (2012:737) ile aynı çizgidedir. Diğer değişkenler ile yalnızlık arasında pozitif bir ilişki vardır. En yüksek pozitif korelasyon fiziksel yetersizlik ile umutsuzluk arasında 0.439 çıkmıştır.

Tablo 4. Açıklayıcı Değişkenlerin Korelasyon Katsayıları

\begin{tabular}{|c|c|c|c|c|c|c|c|c|}
\hline & $\begin{array}{l}\text { Yal- } \\
\text { nızlık }\end{array}$ & Yaş & Cinsiyet & $\begin{array}{l}\text { Aylik } \\
\text { Gelir }\end{array}$ & IG & UM & PP & FY \\
\hline Yalnızlık & 1.0000 & & & & & & & \\
\hline Yaş & -0.1083 & 1.0000 & & & & & & \\
\hline Cinsiyet & -0.0863 & 0.0070 & 1.0000 & & & & & \\
\hline $\begin{array}{l}\text { Aylik } \\
\text { Gelir }\end{array}$ & -0.1507 & 0.3124 & 0.1489 & 1.0000 & & & & \\
\hline IG & -0.0906 & -0.0366 & 0.0404 & 0.0083 & 1.0000 & & & \\
\hline UM & 0.1397 & 0.0374 & 0.0773 & -0.0161 & -0.0862 & 1.0000 & & \\
\hline $\mathrm{PP}$ & 0.1429 & -0.0095 & -0.0194 & -0.1614 & 0.0024 & 0.2125 & 1.0000 & \\
\hline FY & 0.1572 & 0.0032 & 0.0741 & 0.0476 & -0.0430 & 0.4388 & 0.1842 & 1.0000 \\
\hline
\end{tabular}

Logit model koşulmadan önce modelin uyum iyiliğinin üç göstergesine bakılmıştır. Katsayıların anlamlılığı için Omnibus test, model-veri uyumluluğu kontrolü için Hosmer-Lemeshow testi kullanılmış, yalnızlığın doğru sınıflandırılma yüzdesi hesaplanmıştır. Omnibus test hipotezi;

$\mathrm{H}_{0}: \beta_{1}=\beta_{2}=\ldots=\beta_{8}=0$

H1:En az bir katsayı diğerlerinden farklı, şeklinde olup, Tablo 5'te gösterildiği gibi koyu yazılı olan modelin olasılık değeri $\mathrm{p}=0.000<0.05$ olduğundan model anlamlıdır, dolayısıyla $\beta_{1}, \beta_{2}, \ldots, \beta_{8}$ katsayılarının en azından biri sıfırdan farklıdır. Yani, model anlamlıdır (Karagöz, 2018: 83).

Tablo 5. Model Katsayılarının Anlamlılığı İçin Omnibus Testi

\begin{tabular}{lllll}
\hline & & Ki-kare & Serbestlik derecesi & p \\
\hline Adım 1 & Adım & 95.262 & 21 & .000 \\
& Blok & 95.262 & 21 & .000 \\
& Model & $\mathbf{9 5 . 2 6 2}$ & $\mathbf{2 1}$ & $\mathbf{0 0 0}$ \\
\hline
\end{tabular}


Tablo 6, logit modelin bir bütün olarak uyum iyiliği için Hosmer- Lemeshow test sonucunu göstermektedir. Hosmer-Lemeshow ki-kare uyum iyiliği testinde kurulan hipotez: Ho: Teorik model verileri iyi temsil etmektedir; $\mathrm{H}_{1}$ : Teorik model verileri iyi temsil etmemektedir. İlgili tablodaki olasılık değeri 0.809 olup anlamlılık düzeyi olan 0.05 den büyük olması nedeni ile Ho hipotezi reddedilemez. Yani model-veri uyumunun yeterli düzeyde olduğunu söyleyebiliriz.

Tablo 6. Model-Veri Uyumunun Yeterliliği İçin Hosmer-Lemeshow Testi

\begin{tabular}{llll}
\hline Adım & Ki-kare & sd & p \\
\hline 1 & 4.507 & 8 & .809 \\
\hline
\end{tabular}

Tablo 7, yalnızlık hissine ait sinıflandırma tablosu olup, 0.5 kesim değeri ile tahmin edilen doğruluk yüzdelerini sınıflandırmaktadır. Tablo 8 'de gösterildiği gibi çok yalnız hissetmeyenlerin \%57.3'ü ve çok yalnız hissedenlerin \%68.2'si doğru tahmin edilmiştir. Genel olarak \%63'ü doğru tahmin edilmiştir.

Tablo 7. Sinıflandırma Tablosu ${ }^{a}$

\begin{tabular}{|c|c|c|c|c|c|}
\hline \multirow{3}{*}{ Gözlener } & & & \multicolumn{3}{|c|}{ Tahmin Edilen } \\
\hline & & & \multicolumn{2}{|c|}{ Yalnızlık } & \multirow{2}{*}{$\begin{array}{l}\text { Doğru } \\
\%\end{array}$} \\
\hline & & & $\begin{array}{l}\text { Çok yalnız } \\
\text { hissetmeme }\end{array}$ & $\begin{array}{l}\text { Çok yalnız } \\
\text { hissetme }\end{array}$ & \\
\hline \multirow[t]{3}{*}{ Adım 1} & \multirow[t]{2}{*}{ Yalnızlık } & Çok yalnız hissetmeme & 271 & 202 & 57.3 \\
\hline & & Çok yalnız hissetme & 161 & 346 & 68.2 \\
\hline & Genel \% & & & & 63.0 \\
\hline
\end{tabular}

aKesim değeri: 0.5

Tablo 8'de açılayıcı değişkenlerin genel etkilerinin istatistiksel anlamlılı̆̆ını gösteren Ki-kare analiz sonuçları görülmektedir. Tablodaki olasılık değerlerine bakacak olursak yalnızlığı açıklayan en anlamlı değişken $(p=0.0052<0.05)$ fiziksel yetersizlik değişkenidir. Umutsuzluğun genel etkisi $(\mathrm{p}=0.1161>0.05)$ istatistiksel olarak anlamlı değildir. Parasal problemin genel etkisi $(\mathrm{p}=0.0053<0.05)$ istatistiksel olarak anlamlıdır. İnsana güvenin genel etkisi de $(\mathrm{p}=0.049<0.05)$ istatistiksel olarak anlamlıdır. 
Tablo 8. Yalnızlık Üzerine Genel Etkileri Gösteren Ki-kare Sonuç Tablosu

\begin{tabular}{llll}
\hline Açıklayıcı değişken & Ki-kare & Serbestlik Derecesi & Olasıllk (p) \\
\hline Fiziksel yetersizlik & 14.77 & 4 & 0.0052 \\
Umutsuzluk & 7.40 & 4 & 0.1161 \\
Parasal problem & 14.73 & 4 & 0.0053 \\
İnsanlara güven & 6.03 & 2 & 0.0490 \\
\hline
\end{tabular}

Tablo 9'da gösterildiği gibi bağımsız değişkenler yalnızlıktaki toplam değişimin Cox-Snell'e göre \%9.4'ünü ve Nagelkerke'e göre \%12.5'ini açılamaktadır. Ki-kare olabilirlik oran değeri 96.472 ve buna karşılık gelen olasılık değeri $\mathrm{p}=0.000$ modelin bir bütün olarak boş bir modelden (diğer bir ifadeyle tahmin edici içermeyen modelden) önemli ölçüde daha iyi ve uyumlu olduğunu göstermektedir.

Tablo 9. Model Anlamlılı̆̆ı Test İstatistikleri

\begin{tabular}{|c|c|}
\hline Gözlem Sayısı & 980 \\
\hline Log Olabilirlik & -630.458 \\
\hline LR chi2(21) & 96.472 \\
\hline Prob > chi2 & 0.000 \\
\hline McFadden $\mathrm{R}^{2}$ & 0.071 \\
\hline Cox-Snell R² & 0.094 \\
\hline Nagelkerke $\mathrm{R}^{2}$ & 0.125 \\
\hline
\end{tabular}

Tablo 10, modeldeki diğer tüm değişkenler kendi değerlerinde tutulduğunda (sabit), açıklayıcı değişkenlerin her kategorisinin yalnızlık olasılık tahmini ile kendi referans kategorisinin yalnızlık olasılık tahmini arasındaki farkların (ortalama marjinal etkiler) Delta yöntemi ile hesaplanmış olan sonuçlarını göstermektedir. Erkeklerin yalnızlık üzerine etkisi kadınlara göre negatif ve istatistiksel olarak anlamlıdır. Kadınlara göre erkeklerin yalnızlık üzerine etkisi -\%8.4 puandır (mutlak olarak). Diğer bir ifadeyle, erkek olmak çok yalnız hissetme olasılığını \%8.4 puan azaltacaktır. 18-23 yaş grubuna göre 36-41 yaş grubunun yalnız hissetme üzerine ortalama etkisi -\%15.9 puandır. Yani 36-41 yaş kategorisinde olmak 18-23 yaş kategorisinde olmaya göre yalnız hissetme olasılığını \%15.9 azaltacaktır. 6000+ lira geliri olanların 2020 lira altında geliri olanlara göre yalnızlık üzerine ortalama etkisi -\%39.6 puandır. Gelir seviyesi arttıkça yalnız hissetme olasılığının arttığı görülmektedir. Diğer tüm açıklayıcı değişkenler kendi değerlerinde sabit tutulduğunda, insanlara güvenmeyenlere göre insanlara güvenenlerin çok yalnız hissetmenin 
üzerine etkisi -10.6 yüzdelik puandır. Yani, olasılık tahmini yaklaşık \%10.6 puan daha düşüktür. Kesinlikle umutsuz olmayanlara göre kayıtsız (nötr) olanların yalnızlık üzerine etkisi yaklaşık \%11.3 puandır. Diğer tüm açıklayıcı değişkenler kendi değerlerinde sabit tutulduğunda kesinlikle fiziksel yetersizliği olanların çok yalnız hissetme olasılığı, hiç fiziksel yetersizliği olmayanlara göre yaklaşı \%18.6 puan daha yüksektir. Kesinlikle parasal bir problemi olmayanlara göre kesinlikle parasal problemi olanların yalnızlık üzerine etkisi yaklaşık \%12.9 puandır.

Tablo 10. Açıklayıcı Değişkenlerin Yalnızlık Üzerine Marjinal Etkileri

\begin{tabular}{|c|c|c|c|c|c|c|c|}
\hline Yalnızlık & $\mathbf{b}$ & $e^{b}$ & $\mathrm{dy} / \mathrm{dx}$ & $\begin{array}{l}\text { Standart } \\
\text { hata }\end{array}$ & $\mathrm{p}$ & $\begin{array}{l}\text { \%95 } \\
\text { Aralığı }\end{array}$ & Güven \\
\hline Cinsiyet & & & & & & Alt & Üst \\
\hline Erkek & -.370 & .691 & -.084 & .032 & 0.008 & -.146 & -.022 \\
\hline \multicolumn{8}{|l|}{ Yas } \\
\hline $24-29$ & -.035 & .966 & -.008 & .036 & 0.827 & -.079 & .063 \\
\hline $30-35$ & -.447 & .640 & -.102 & .053 & 0.056 & -.207 & .003 \\
\hline $36-41$ & -.702 & .496 & -.159 & .067 & 0.018 & -.290 & -.027 \\
\hline $42-47$ & -.440 & .644 & -.100 & .101 & 0.322 & -.299 & .098 \\
\hline \multicolumn{8}{|l|}{ Aylık gelir } \\
\hline $2020-6000$ & -.476 & .621 & -.109 & .041 & 0.007 & -.189 & -.030 \\
\hline $6000+$ & -2.06 & .128 & -.396 & .133 & 0.003 & -.657 & -.134 \\
\hline \multicolumn{8}{|l|}{ Umutsuzluk } \\
\hline Katılmıyorum & .098 & 1.103 & .023 & .042 & 0.591 & -.060 & .105 \\
\hline $\begin{array}{l}\text { Ne katıliyorum ne de } \\
\text { katılmiyorum }\end{array}$ & .495 & 1.641 & .113 & .051 & 0.026 & .014 & .212 \\
\hline Katıliyorum & .455 & 1.577 & .104 & .063 & 0.101 & -.020 & .228 \\
\hline Kesinlikle katıliyorum & .232 & 1.261 & .053 & .089 & 0.550 & -.121 & .228 \\
\hline \multicolumn{8}{|l|}{ Fiziksel yetersizlik } \\
\hline Katılmıyorum & .587 & 1.799 & .136 & .044 & 0.002 & .050 & .221 \\
\hline $\begin{array}{l}\text { Ne katıliyorum ne de } \\
\text { katılmiyorum }\end{array}$ & .626 & 1.871 & .144 & .049 & 0.003 & .049 & .240 \\
\hline Katıliyorum & .695 & 2.003 & .160 & .061 & 0.008 & .041 & .279 \\
\hline Kesinlikle katıliyorum & .814 & 2.257 & .186 & .082 & 0.023 & .026 & .346 \\
\hline \multicolumn{8}{|l|}{ İnsana güven } \\
\hline $\begin{array}{l}\text { Ne güveniyorum ne de } \\
\text { güvenmiyorum }\end{array}$ & -.354 & .702 & -.080 & .034 & 0.018 & -.147 & -.014 \\
\hline Güveniyorum & -.466 & .627 & -.106 & .045 & 0.018 & -.194 & -.018 \\
\hline \multicolumn{8}{|l|}{ Parasal problem } \\
\hline Katılmiyorum & -.215 & .807 & -.049 & .057 & 0.389 & -.161 & .063 \\
\hline $\begin{array}{l}\text { Ne katıliyorum ne de } \\
\text { katılmiyorum }\end{array}$ & -.068 & .934 & -.016 & .053 & 0.767 & -.118 & .087 \\
\hline Katılıyorum & .058 & .943 & -.013 & .055 & 0.808 & -.121 & .095 \\
\hline Kesinlikle katılıyorum & .576 & 1.778 & .129 & .054 & 0.016 & .025 & .234 \\
\hline
\end{tabular}




\section{Tartışma}

Bu çalışmadaki bireylerin yalnızlık hislerini etkileyen değişkenler; gelir, fiziksel yetersizlik, umutsuzluk, parasal problemler ve insanlara güven olarak belirlenmiştir. Kanıtlar, her beşinin de yalnızlık hissi için risk teşkil ettiği sonucuna ulaşılmıştır. Yalnızlık hissini en çok etkileyen değişkenlerin gelir ve fiziksel yetersizlik olduğu sonucuna varılmıştır. Yalnızlık hissinin istatistiksel olarak cinsiyet ve yaş gibi demografik değişkenlerle ilişkili olduğu, ancak ikamet değişikliği, eğitim durumu, iş durumu, çalışma alanı ve yaşanılan yer ile ilişkili olmadığı görülmektedir. Diğer yaş gruplarına göre gençlerin yalnızlık üzerine etkisi daha yüksek çıkmıştır. Bu sonuca, kişisel özerklik isteği, gelişimsel değişiklikler, olgunlaşma (Brennan, 1982) ve muhtemelen internet-sosyal medya bağımlılığ katkı sağlar. Genel olarak, insanlara güven ve sosyal iletişim vasitasıyla sosyal sermayenin yalnızlığı etkilemesi beklenir (Van der Valk, 2017, s.8). Sosyal sermaye değişkenleri içerisinde insana güvenin yalnızlık hissini açıklamada arkadaş ve aile bireyleri ile görüşme sıklığından daha önemli olduğu görülmektedir. İnsana güven, yalnızlı̆̆ı en aza indirgeyecek olan güçlü bir sosyal ağ oluşturmak için gereklidir. Bu sonuç, Stanfeld (1999)'in ulaştığı "yalnızlık yetersiz sosyal ağa sahip olmakla ilişkilidir" sonucunu desteklemektedir. İnsana güvenin yalnızlık üzerine etkisi cinsiyete göre farklılık göstermiştir. İnsana güvenen erkeklerin kadınlara göre yalnızlık etkilerinin daha yüksek olduğu ve dolayısıyla kadınların sosyal ilişkilerinin erkeklere göre daha güçlü olduğu görülmektedir. Bu durum, doğası gereği kadınların erkeklerden daha duygusal olması nedeniyle diğer insanlarla duygusal ilişkide olması ve sosyal problemlerinin çözümünde daha katılımcı davranması ile açıklanabilir (Kawachi ve Berkman, 2001). Ancak fiziksel yetersizlik bireylerin sosyal sermayesini negatif etkilemekte ve onları yalnızlığa sürüklemektedir.

Adana kültüründe arkadaş, aile ve esnaf çevresinde samimiyete istinaden kendi aralarında verilen veya alınan borçların ödenmemesi sosyal ilişkilere olumsuz yönde yansımakta ve sürekli borç isteyen bireyleri yalnızlığa, umutsuzluğa sürüklemekte, güven kaybına uğratmakta ve görüşme sıklı̆̆ı ve kalitesini azaltmaktadır. Diğer taraftan sosyal ilişkilerin işlevsel yeteneği ve refahı arttırdığı bilinmektedir, ancak sınırlı 
işlevsel yeteneği kişinin sosyal bağları sürdürme yeteneğini de etkileyebilir. İşlerini kendi başına yapmakta fiziksel yeterliliğe sahip olamayan bireylerin çalışamamaktan dolayı gelir sıkıntısı, bakımevleri yetersizliği ve ücretlerinin yüksek olması nedeniyle yakın aile çevresinde kalma zorunluluğu, kısmen/sürekli olarak ikinci kişilerden yardım isteme ihtiyaçları kendilerini çıkmazda ve yalnız hissetmeye ve yaşama ümitlerini yitirmelerine neden olmaktadır.

\section{Sonuç}

Modelde kullanılan açıklayıcı değişkenler içerisinde yüksek gelir ve fiziksel yetersizlik yalnızlık üzerine en güçlü etkiye sahiptir. Genel olarak, parasal problem ve fiziksel yetersizlik arttıkça yalnızlık etkisinin arttığı görülmektedir. Kadınlara göre erkeklerin yalnızlık etkisi daha düşüktür. Yaş arttıkça yalnızlık etkisi kesikli V şeklinde davranış göstermektedir ve bu sonuç Perlman (1990, s.10) çalışmasında kullanılan (Radloff, 1982) NIMH anketi sonucuyla aynı çizgidedir. Aylık gelir ve insana güven arttıkça yalnızlık etkisinin azaldığı görülmektedir.

Fiziksel yetersizliği olan bireylerin yalnızlık hislerini ortadan kaldırabilecek önlemlerin alınabilmesi oldukça zor olsa da en azından yalnızlığı azaltabilecek devlet politikalarının üretilmesi ve uygulanması mümkündür. Yalnızlı̆̆ın azaltılmasında en çok önerilen yöntemlerden biri sosyal temasın gelişimini teşvik eden bir ortamdır (Dill ve Anderson, 1999, s.115). Fiziksel yetersizliği olanların tıbbi ve sosyal destek alabileceği ve sosyal bir ağ oluşturabileceği şekilde tasarlanmış sağlıklı yaşam evlerinin çoğaltılıp ihtiyaç sahiplerine süreli veya süresiz düşük ücretle tahsis edilmesi ve yaşamın bir parçası haline getirilmesi gerekmektedir. Gelecekteki çalışmada yalnızlık ve sosyal izolasyonun umutsuzluk üzerine etkisini araştırmak toplumsal araştırmalar açısından önemli olacaktır. 


\title{
EXTENDED ABSTRACT
}

\section{The Effect of Physical Disability, Hopelessness, Monetary Problem and Social Capital on the Feeling of Loneliness}

\author{
Gülsen Kıral - Can Mavruk - Ersin Kıral \\ Çukurova University, Ömer Halisdemir University
}

Some studies on loneliness in Adana have been found in the literature. As a result of the study conducted on 899 high school students attending public schools in Adana, the loneliness levels of adolescents with high violence tendency were found to be high (Avcı and Yıldırım, 2014); Using the UCLA loneliness scale, it was estimated how the temperament style of Çukurova University students affected loneliness (Çeçen, 2007). However, the effect of physical insufficiency, hopelessness, financial problems and social capital of adults on the feeling of loneliness in Adana has not been investigated in the literature. In this study, loneliness is considered as a subjective nature apart from the objective nature of social isolation.

This study investigates important determinants of loneliness of individuals living in Adana. In January-February 2019, a 70-question Life Quality Analysis Survey conducted by simple random sampling to reveal demographic, socio-economic and psychological status was applied to 980 adults living in Adana. The most appropriate econometric model was created using significant variables which are thought to affect the feeling of loneliness such as demographic, economic, health, spatial, social capital, physical inadequacy, hopelessness, monetary problem (financial distress), and trust in people in general. Explanatory dummy variables were coded as categorical indicators except for monthly income, first marriage age and the number of people living together in the family. Among the demographic variables, the categories 18-23, 24-29, 30-35, 3641 and $42-47$ for age were coded by 1, 2, 3, 4 and 5 respectively, female and 
male for gender by 0 and 1, unmarried, married, divorced or separated, widowed and engaged for marital status by 1, 2, 3, 4 and 5, and illiterate, primary school, high school, vocational high school, university, postgraduate for educational status by 1, 2, 3, 4, 5 and 6 . In order to measure physical insufficiency and hopelessness, respondents were asked to what extent they agree to the statements "I have physical insufficiency" and "my goal is unlikely to be realized". The options "strongly disagree ", "disagree", "neither agree nor disagree", "agree" and strongly agree" are provided. In this study, "my goal is unlikely to be realized" was conceptualized as hopelessness. In order to measure social capital, the question "to what extent do you generally trust in people? was asked and the options were categorized as "never trust", "do not trust ", "neutral", "do trust" or "trust a lot". The answers were coded with 1, 2, 3, 4, 5 respectively. In order to measure loneliness, "no" or "yes" options are provided for the question "Did you feel very lonely and away from other people during the last week?" The answers were coded with 0 and 1, respectively.

All logit models assume a continuous dependent latent variable $\left(\mathrm{Y}^{*}\right)$ that is linearly related to the independent variables:

$$
\mathrm{Y}^{*}=\mathbf{X} \beta+\varepsilon \quad \varepsilon \sim \operatorname{Logit}\left(0, \Lambda^{2} / 3\right)
$$

A logit model was created for hopelessness, physical inadequacy, monetary problem, social capital nominal independent variables and loneliness dependent variable together with demographic variables. According to this model, the probability of an individual feeling alone is calculated by

$$
\mathrm{P}(\mathrm{Y}=1)=1 /(1+\exp (-\mathrm{X} \beta))
$$

In this formula,

$$
\boldsymbol{X} \beta=\beta_{0}+\beta_{1} D_{1}+\beta_{2} D_{2}+\beta_{3} S E+\beta_{4} A G+\beta_{5} F Y+\beta_{6} U M+\beta_{7} P P+\beta_{8} I G
$$

where $\mathrm{D}_{1}$ indicates gender, $\mathrm{D}_{2}$ age, $S E$ monthly income, $F Y$ physical inadequacy, UM hopelessness, $P P$ monetary problem, and IG trust in human. 
In logit models, when all other variables are held constant or at their values (averages), the marginal effect is the slope of the probability curve that correlates $X_{k}$ with probability $\mathrm{P}(\mathrm{Y}=1 \mid \mathrm{X})$. Accordingly, the marginal effect of FY on loneliness is calculated by

$$
\begin{aligned}
\partial \mathrm{P}(\mathrm{Y}=1) / \partial \mathrm{\partial F}= & {\left[\exp (\mathbf{X} \beta) /\left(1+\exp (\mathbf{X} \beta)^{2}\right](\partial(\mathbf{X} \beta) / \partial \mathrm{FY})=\left[\exp (\mathbf{X} \beta) /\left(1+\exp (\mathbf{X} \beta)^{2}\right]\right.\right.} \\
& \beta_{1}=\mathrm{P}(\mathrm{Y}=1)[1-\mathrm{P}(\mathrm{Y}=1)] \beta_{1}=\mathrm{P}(\mathrm{Y}=1) \mathrm{P}(\mathrm{Y}=0) \beta_{1} .
\end{aligned}
$$

Descriptive results indicated that approximately $42 \%$ of respondents had financial problems, $14 \%$ had a physical deficiency, $13 \%$ were hopeless and $45 \%$ did not trust people. Loneliness odds ratio is calculated by $\mathrm{p} /(1-$ $p)=(507 / 980) /(1-507 / 980)=0.517 /(1-0.517)=0.517 / 0.483=1.07$

There was a negative correlation between age, gender, monthly income, trust in people and loneliness, while there was a positive relationship between hopelessness and loneliness. This result is in line with Pehlivan et al. (2012: 737). There is a positive relationship between loneliness and other variables. The highest positive correlation was 0.439 between physical insufficiency and hopelessness.

Before the Logit model was run, three indicators of goodness of fit of the model were examined. Omnibus test was used for the significance of the coefficients, Hosmer-Lemeshow test was used for the model-data compatibility check, and the percentage of accurate classification of the loneliness was calculated. $57.3 \%$ of those who did not feel very lonely and $68.2 \%$ of those who felt very lonely were estimated correctly. Overall, $63 \%$ were estimated correctly. The most significant variable explaining loneliness $(p=0.0052<0.05)$ was physical disability. The overall effect of hopelessness $(p=0.1161>0.05)$ was not statistically significant. The overall effect of the monetary problem $(p=0.0053<0.05)$ was statistically significant. The overall effect of trust in people $(p=0.049<0.05)$ was also statistically significant. When all other variables in the model are held at their own values, the differences between the loneliness probability estimate of each category of explanatory variables and the loneliness probability estimate of their reference category (average marginal effects), 
and standard deviations (by Delta method) are estimated. The effect of men on loneliness is negative and statistically significant for women. The effect of men on loneliness relative to women is $-8.4 \%$ (absolute). In other words, being a man will reduce the chance of feeling very lonely by $8.4 \%$. The average effect of 36-41 age group on feeling lonely compared to 18-23 age group is $-15.9 \%$. In other words, being in the $36-41$ age category will reduce the probability of feeling lonely by $15.9 \%$ compared to being in the 18-23 age category. The average effect of those who have 6000+ lira income on loneliness compared to those who have income below 2020 lira is $39.6 \%$. The higher the income level, the more likely it is to feel alone. When all other explanatory variables are kept at their own values, the effect of trusting people on feeling very lonely compared to those who do not trust people is -10.6 percentage points. So, trust in people relative to no trust decreases the probability of feeling very lonely by about 10.6 percentage points. Relative to definitely not hopeless, the effect of being indifferent (neutral) on loneliness is approximately 11.3 percent. When all other explanatory variables are held at their own values, the probability of feeling very lonely in those with physical disability is $18.6 \%$ higher than those without physical disability. The effect of financial problems on feeling of loneliness compared to no monetary problems is approximately 12.9 percent.

Consequently, among the explanatory variables used in the model, high income and physical insufficiency have the strongest effect on loneliness. In general, the effect of loneliness increases as the financial problem and physical insufficiency increase. The loneliness effect of men is lower than women. As age increases, the effect of loneliness shows discrete V-shaped behavior and this result is in line with the results of the NIMH questionnaire used in the Perlman (1990, p.10) study (Radloff, 1982). It is seen that the loneliness effect decreases as monthly income and trust increases. Although it is very difficult to take measures to eliminate the feelings of loneliness of individuals with physical disabilities, at least 
it is possible to produce and implement state policies that can reduce loneliness. One of the most recommended methods for reducing loneliness is an environment that promotes the development of social contact (Dill and Anderson, 1999, p.115). The wellness houses designed to provide medical and social support and to form a social network to those with physical disabilities should be replicated and allocated to those in need for a low or indefinitely low wage and become a part of life.

In the future study, it will be important to investigate the effect of loneliness and social isolation on hopelessness in terms of social studies.

\section{Kaynakça / References}

Andersson, L. (1998). Loneliness research and interventions: A review of the literature. Aging \& Mental Health, 2(4), 264-274.

Bekhet, A. K., Zauszniewski, J. A. ve Nakhla, W. E. (2008). Loneliness: A concept analysis. Nursing Forum, 43(4), 207-213.

Cacioppo, J. T. ve Patrick, W. (2008). Loneliness: Human nature and the need for social connection. New York: W. W. Norton \& Company.

Cacioppo, J. T., Hawkley, L. C., and Thisted, R. A. (2010). Perceived social isolation makes me sad: 5-year cross-lagged analyses of loneliness and depressive symptomatology in the Chicago health, aging, and social relations study. Psychol. Aging, 25, 453-463.

Coleman, J. S. (1988). Social capital in the creation of human capital. The American Journal of Sociology, 94, S95-S120.

Çeçen, A. R. ve Cenkseven, F. (2007). Psychological well-being in predicting loneliness among university students. Ç.Ü. Sosyal Bilimler Enstitüsü Dergisi, 16, 109-118.

Danış, M. Z. (2009). Türkiye'de yaşlı nüfusun yalnızlık ve yoksulluk durumları ve sosyal hizmet uygulamaları açısından bazı çıkarımlar. Toplum ve Sosyal Hizmet, 20(1), 67-83.

Dill, J. C. ve Anderson, C. A. (1999). The interactional nature of depression: Advances in interpersonal approaches. (T. Joiner, and J. C. Coyne, Eds.), Loneliness, Shyness, And Depression: The Etiology And Interrelationships Of Everday Problems In Living, (p. 93-125). Washington DC: APA. 
Ernst, J. M. ve Cacioppo, J. T. (1999). Lonely hearts: Psychological perspectives on loneliness. Applied and Preventive Psychology, 8(1), 1-22.

Hawkley, L. C. ve Cacioppo, J. T. (2009). Loneliness. (H.R.S. Sprecher Ed.), Encyclopedia of human relationships (p. 985-990). Thousand Oaks, CA: Sage.

Hawkley, L. C., Thisted, R. A., Masi, C. M. ve Cacioppo, J. T. (2010). Loneliness predicts increased blood pressure: 5-year cross-lagged analyses in middle-aged and older adults. Psychol. Aging, 25, 132-141.

Holt-Lunstad, J., Smith, T. B., Baker, M., Harris, T. ve Stephenson, D. (2015). Loneliness and social isolation as risk factors for mortality: a metaanalytic review. Perspect. Psychol. Sci. 10, 227-237.

Karagöz, Y. (2018). Bilimsel araştırma yöntemleri ve yayın etiği. Ankara: Nobel Akademik Yayıncılık.

Kawachi, I. ve Berkman, L. F. (2001). Social ties and mental health. J. Urban Health, 78(3), 458-467.

Kıral, E. ve Mavruk, C. (2017). Regional unemployment disparities in Turkey. Finans, Politik ve Ekonomik Yorumlar, 54(634), 107-134.

Lauder, W., Mummery, K., Jones, M., and Caperchione, C. (2006). A comparison of health behaviours in lonely and non-lonely populations. Psychol. Health Med., 11, 233-245.

Pehlivan, S., Ovayolu, Ö., Ovayolu N., Sevinc, A. ve Camc1, C. (2012). Relationship between hopelessness, loneliness, and perceived social support from family in turkish patients with cancer. Support Care Cancer, 20, 733-739.

Perlman, D. (1990). Age differences in loneliness: A meta-analysis. Vancouver, BC: University of British Columbia (ERIC Document Reproduction Service No. ED326767).

Pradhan, G. (2016). Social integration and its correlation with loneliness. Miami University, Population and Social Gerontology. 04.03.2019 tarihinde https://etd.ohiolink.edu/!etd.send file?accession=miami1470270402\&disposition=inline adresinden erişilmiştir.

Radloff, L. (1982). Data from the center for epidemiologic studies. Analysis of unpublished data, National Institute of Mental Health.

Rokach, A. (1988). Theoretical approaches to loneliness: From a univariate to a multidimensional experience. Review of Existential Psychology and Psychiatry, 19, 225-254. 
Rokach, A. (2012). Loneliness updated: An introduction. The Journal of Psychology, 146(1-2), 1-6.

Rokach, A. (2014). Loneliness of the marginalized. Open Journal of Depression, 3, 147-153.

Rotenberg, K. J., Addis, N., Betts, L. R., Corrigan, A., Fox, C., Hobson ,...,

Misra, N. (2009). Loneliness, depression and sociability in old age. Ind Psychiatry J. 18(1), 51-55.

Stanfeld, S. (1999). Social determinants of health. (M. Marmot, and R. Wilkinson Eds.), Social Support and Social Cohesion (p. 155-178). Oxford: Oxford University Press.

Valk, I. V. D. (2017). Social capital as a solution to mental health problems: The effects of social capital on depression and loneliness via the effect of social cohesion and civic engagement. Master Thesis, Utrecht University, Utrecht, Netherlands.

Valtorta, N. K., Kanaan, M., Gilbody, S., Ronzi, S., and Hanratty, B. (2016). Loneliness and social isolation as risk factors for coronary heart disease and stroke: systematic review and meta-analysis of longitudinal observational studies. Heart, 102, 1009-1016.

Weiss, R. S. (1973). Loneliness: The experience of emotional and social isolation. Cambridge: MIT Press.

Wenger, G., Davies, R., Shahtahmasebi, S. ve Scott, A. (1996). Social isolation and loneliness in old age: Review and model refinement. Ageing and Society, 16(3), 333-358.

Williams, R. (2012). Using the margins command to estimate and interpret adjusted predictions and marginal effects. The Stata Journal, 12(2), 308331.

Zavaleta, D., Samuel, K. ve China, M. (2014). Social Isolation: A conceptual and measurement proposal. OPHI Working Paper No. 67, Oxford.

\section{Kaynakça Bilgisi / Citation Information}

Kıral, G., Mavruk, C. ve Kıral, E. (2019). Fiziksel yetersizlik, umutsuzluk, parasal problem ve sosyal sermayenin yalnızlık hissi üzerine etkisi.OPUS-Uluslararası Toplum Araştırmaları Dergisi , 14(20), 239261. DOI: 10.26466-/opus.568540 